\title{
Specific IgG avidity in acute and chronic human fascioliasis
}

\author{
L.M. Abou-Basha, 'A.Y. Shehab, 'M.M. Osman ' and HF. Farag'
}

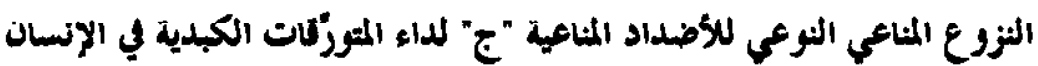

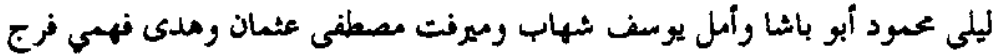

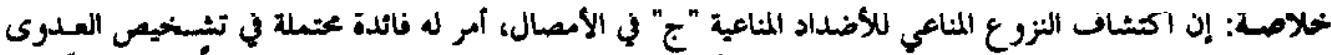

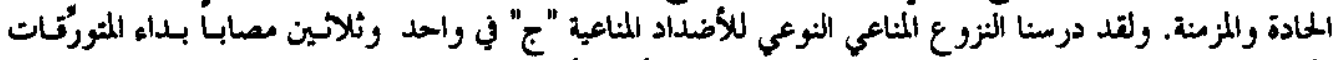

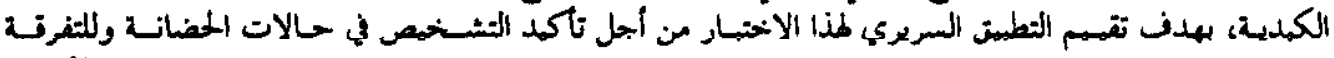

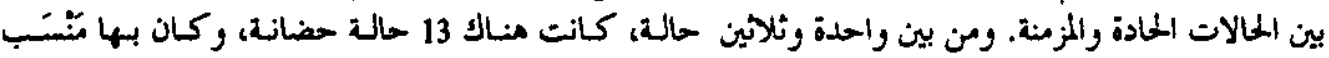

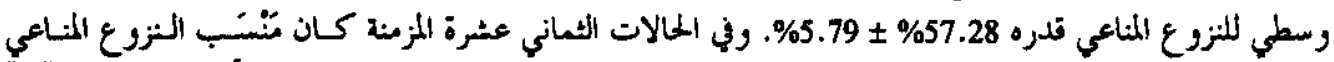

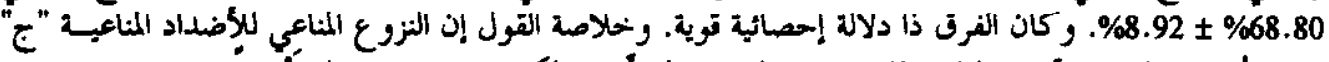

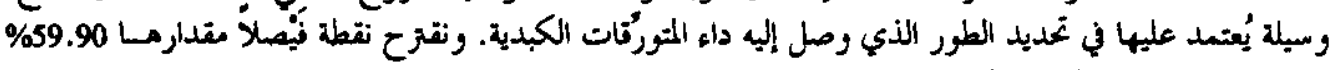

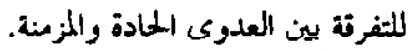

ABSTRACT The detection of lgG avidity in sera is potentialiy useful in the diagnosis of acute and chronic infection. We studied IgG avidity in 31 patients with fascioliasis, with the aim of evaluating the clinical application of this test to confirm the diagnosis of incubating cases and to distinguish between acute and chronic cases. Of the 31 cases, 13 were incubating and had a mean avidity index of $57.28 \pm 5.79 \%$. The 18 chronic cases had an avidity index of $68.80 \pm 8.92 \%$. The difference was highly significant. We conclude that Iga avidity is a roliable moans of identifying the stage of fasoioliasis and ouggoat a out-oft point of $50.00 \%$ to distinguish between acute and chronic infection.

\section{Avldité spécifique des IgG dans la fasciolase chronique et algué chez l'homme}

RESUME La détection d'une avidité des IgG dans les sérums est potentiellement utile pour le diagnostic de l'infection chronique et aiguee. Nous avons étudié l'avidité des IgG chez 31 patients atteints de fasciolase dans le but d'évaluer l'application clinique de ce test pour confirmer le diagnostic des cas en incubation et de distinguer entre les cas chroniques et aigus. Sur les 31 cas, 13 étaient en incubation et avaient un index d'avidité moyen de $57,28 \pm 5,79 \%$. Les 18 cas chroniques avaient un index d'avidité de $68,80 \pm 8,92 \%$. La différence était hautement significative. Nous concluons que l'avidité des $\mathrm{ggG}$ est un moyen fiable d'identifier le stade de la fasciolase et suggérons un seuil de $59,90 \%$ pour faire la distinction entre l'infection chronique et aigue.

'Department of Parasitology, Medical Research Institute, University of Alexandria, Alexandria, Egypt. Received: 01/02/00; accepted: 25/04/00

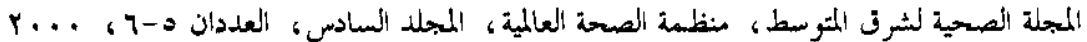




\section{Introduction}

Fascioliasis is recognized as an emerging human iufection. The parasite infects a multiplicity of hosts in whom maturation and oviposition start at different times. In humans, the parasitic incubation (pre-patent) period has been estimated as 4 months [l]. During this period, the immature parasites affect the liver and form necrotic areas that end in fibrosis [2]. Early in infection, eosinophilia, high antibody titres and high circulating antigen values are the means of diagnosis [3]. With the appearance of ova in the stools, these values are significantly lowered [4].

Antibody avidity refers to the strength of interaction of an antibody with a multivalent antigen. Depending upon the strength of this binding, the complex formed may or may not be dissociated. Antibody avidity is low after primary antigenic challenge, matures with time and it usually involves IgG antibodies [5-7].

Recently, an assay measuring the antigen-binding avidity of IgG antibodies has been developed to distinguish the low-affinity antibodies produced at an early stage of infection from those with a higher-binding affinity that reflects past immunity. This IgG avidity test has been valuable with many pathogens as both a front-line assay and as a means of distinguishing primary from secondary infections [8-10]. It is also helpful in assessing the time of the initial antigenic challenge. Diagnosis of the acute phase of fascioliasis is important, as treatment is effective during this stage and can prevent the harmful sequelae of the disease [II].

We aimed to study specific IgG avidity during pre- and post-patency in human fascioliasis. This may confirm the diagnosis early after infection, and it may also clarify the duration of infection.

\section{Patients and methods}

A total of 31 patients with single fascioliasis were studied (age range: 15-45 years), 13 of whom were incubating the infection and 18 were passing eggs in their stools. Patients in the acute stage were diagnosed clinically by pain in the right hypochondrium with fever, haematologically by leukocytosis with high eosinophilic count, and serologically by high specific antibody level together with negative stool examination [II]. Patients in the established phase (chronic stage) were diagnosed by the detection of ova in stools. Intensity of infection was established after examination of two thick-smear Kato slides of $41.70 \mathrm{mg}$ each [12]. Sera were collected from all the patients and used in the indirect haemagglutination test (IHAT) (Fumouse Kit, France) and in the study of specific IgG avidity.

We used the Rivera Marrero et al. method for antigen preparation [13]. Live aduit worms of Fasciola gigantica were placed in phosphate-buffered saline containing 0.8 mmol phenylmethylsulfonylfluoride for 3 hours at $37^{\circ} \mathrm{C}$. After incubation, the worms were removed and the medium containing the excretory-secretory (E/S) product was centrifuged. The supernatant was collected and its protein content determined [14]. This antigen has been found to be $100 \%$ specific for acute and chronic fascioliasis using IgM and IgG conjugates respectively [15].

Tn nerform the IgG avidity enzymelinked immunosorbent assay (ELISA) test, an enzyme immunoassay for determination of IgG antibody to Fasciola was carried out using $\mathrm{E} / \mathrm{S}$ antigen according to the method described by Voller et al. [16]. To measure the avidity of specific IgG, the test was repeated after adding urea solution to the washing buffer. Urea acts as a hydrogen-bond-disrupting agent and results in 
dissociation of low-avidity antibodies, whereas high-avidity antibodies remain antigen bound [17]. A pilot study using $6 \mathrm{M}$ and $8 \mathrm{M}$ urea showed $6 \mathrm{M}$ urea gave the clearest separation and thus was used in the present work. After measuring Fasciolaspecific avidity using the "bind and break" method, an avidity index (AI) was calculated as follows:

\section{$\frac{\text { absorbance after urea wash }}{\text { absorbance after phosphate buffer }} \times 100$}

$\mathrm{AI}$ is an indicator of avidity. Therefore, a low index means low avidity while a high index denotes high avidity. To compare cases at the individual level, a cut-off point to differentiate between acute and chronic cases was suggested (after studying other possibilities) using the following formula:

$$
\begin{gathered}
\text { AI cut-off }=\text { mean AI in established cases } \\
-1 \text { standard deviation }
\end{gathered}
$$

\section{Results}

In the incubating group, the IHAT titres varied between $1 / 320$ and $1 / 2560$, while the group with established infection showed negative results, except for two with titres of $1 / 160$ and $1 / 640$ (lables 1 and 2). Depending on the two Kato slides, the intensity of infection in established cases varied between $12 \mathrm{eggs} / \mathrm{g}$ of stool and $312 \mathrm{eggs} / \mathrm{g}$ of stool (Table 2).

Table 3 and Figure 1 show AI in acute and chronic cases of fascioliasis. In the incubating group, AI values ranged from $47.15 \%$ to $68.73 \%$ with a mean of $57.28 \pm$ $5.787 \%$. Patients with an established infection had AI values ranging from $54.48 \%$ to $91.36 \%$ with a mean of $68.80 \pm 8.921 \%$. The difference between the two groups was statistically significant $(P<0.001)$. The mean AI cut-off was $59.90 \%$. Thus, values $\leq 59.90 \%$ denoted acute infection and those $>59.90 \%$ denoted chronic infec-

Table 1 Indlrect haemagglutination titres and avidity index in patlents with acute fascioliasis

\begin{tabular}{lccc}
\hline $\begin{array}{l}\text { Reciprocal indirect } \\
\text { haemagglutination }\end{array}$ & Optical density values & Avidity index (\%) \\
titres & Without urea & With urea & \\
\hline 2560 & 1.036 & 0.565 & 54.54 \\
1280 & 0.889 & 0.518 & 58.27 \\
1280 & 0.784 & 0.427 & 54.46 \\
2560 & 0.644 & 0.331 & 51.40 \\
640 & 0.324 & 0.187 & 57.72 \\
640 & 0.789 & 0.372 & 47.15 \\
2560 & 0.830 & 0.512 & 61.69 \\
1280 & 0.971 & 0.583 & 60.04 \\
1280 & 0.915 & 0.537 & 58.69 \\
640 & 1.084 & 0.745 & 68.73 \\
320 & 0.742 & 0.374 & 50.40 \\
640 & 0.875 & 0.507 & 57.94 \\
1280 & 0.698 & 0.444 & 63.61 \\
\hline
\end{tabular}

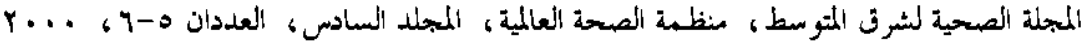


Table 2 Egg counts, indirect haemegglutinatlon titres and avidity Index in patients with chronic fescioliasls

\begin{tabular}{|c|c|c|c|c|}
\hline \multirow{2}{*}{$\begin{array}{l}\text { Mean egg count } \\
\text { perg stool }\end{array}$} & \multirow{2}{*}{$\begin{array}{c}\text { Reciprocal indirect } \\
\text { haemagglutination } \\
\text { thtres }\end{array}$} & \multicolumn{2}{|c|}{ Optical density values } & \multirow{2}{*}{$\begin{array}{c}\text { Avidity } \\
\text { Index (\%) }\end{array}$} \\
\hline & & Without uree & With urea & \\
\hline 216 & $-v e$ & 1.021 & 0.667 & 65.33 \\
\hline 60 & $-v e$ & 0.965 & 0.685 & 71.00 \\
\hline 72 & $-v e$ & 0.961 & 0.878 & 91.36 \\
\hline 60 & $-v e$ & 0.597 & 0.358 & 60.00 \\
\hline 72 & $-v \theta$ & 0.401 & 0.268 & 66.83 \\
\hline 132 & $-v e$ & 0.498 & 0.316 & 63.45 \\
\hline 48 & $-v e$ & 0.676 & 0.539 & 79.73 \\
\hline 60 & $-v e$ & 0.570 & 0.402 & 70.53 \\
\hline 24 & 160 & 0.782 & 0.426 & 54.48 \\
\hline 12 & $-v e$ & 0.493 & 0.312 & 63.29 \\
\hline 90 & $-\mathbf{v e}$ & 0.325 & 0.214 & 65.85 \\
\hline 12 & $-v e$ & 0.726 & 0.445 & 61.29 \\
\hline 84 & $-v e$ & 0.941 & 0.625 & 66.42 \\
\hline 312 & 640 & 0.692 & 0.467 & 67.49 \\
\hline 96 & $-v e$ & 0.359 & 0.229 & 63.79 \\
\hline 60 & $-v e$ & 0.530 & 0.449 & 83.46 \\
\hline 108 & $-v_{\theta}$ & 0.719 & 0.494 & 68.71 \\
\hline 24 & $-v e$ & 1.026 & 0.776 & 75.63 \\
\hline
\end{tabular}

Table 3 Avidity Index in acute and chronic fasciollasis

\begin{tabular}{|c|c|c|}
\hline \multirow[t]{2}{*}{ Patfents } & \multicolumn{2}{|c|}{ Avidlty Index } \\
\hline & Pange (\%) & Mean $\pm s(\%)$ \\
\hline $\begin{array}{c}\text { Acute cases } \\
(n=13)\end{array}$ & $4.15-68.73$ & $57.28 \pm 5.79$ \\
\hline $\begin{array}{l}\text { Chronic cases } \\
\qquad(n=18)\end{array}$ & $54.48-91.36$ & $68.80 \pm 8.92$ \\
\hline
\end{tabular}

Table 4 Accuracy of avidity index at the suggested cut-off point

\begin{tabular}{lcc}
\hline $\begin{array}{l}\text { Avidity index } \\
\text { (\%) }\end{array}$ & \multicolumn{2}{c}{ True sltuation: } \\
Acute cases & Chronic cases \\
\hline$\leq 59.9$ (acute) & 9 & 1 \\
$>59.9$ (chronic) & 4 & 17 \\
Total & 13 & 18 \\
\hline
\end{tabular}

"According to stool examination and IHAT.

Sensitivity to diagnose acute cases $=9 / 13 \times 100=$ $69.2 \%$.

Sensitivity to diagnose chronic cases $=17 / 18 \times$ $100=94.4 \%$.

Overall accuracy $=26 / 31 \times 100=83.9 \%$. 


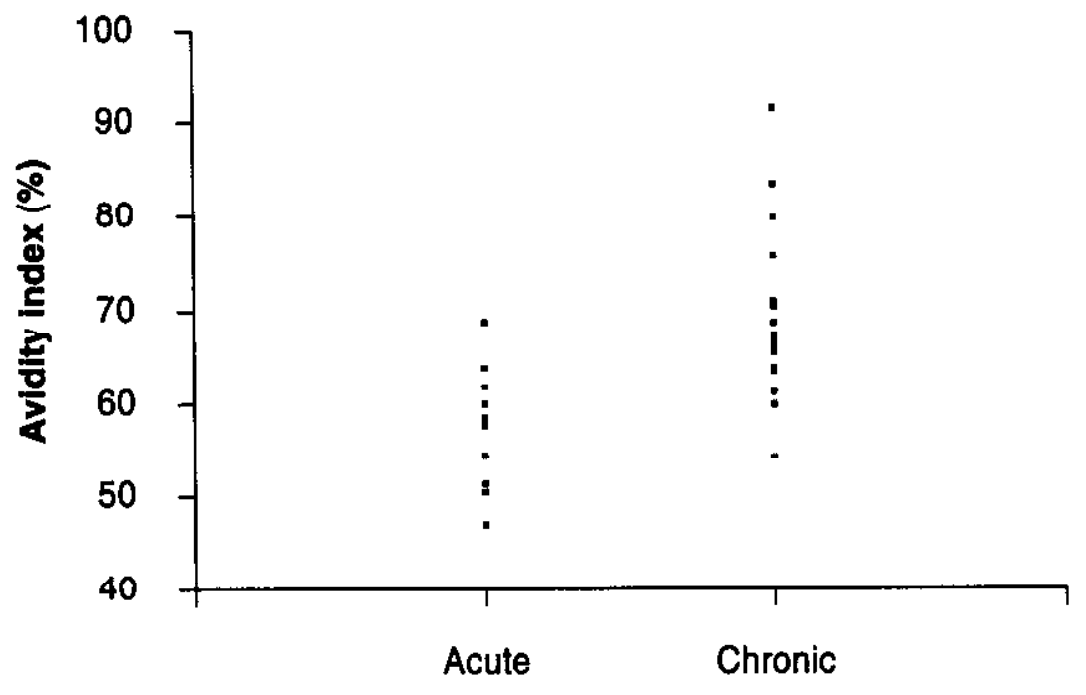

Figure 1 Avidity index in acute and chronic cases of fasciolias is

tion. Four patients in the acute phase had values above this point and one with established infection had a value below $59.90 \%$. The validity of this cut-off point is examined in Table 4.

\section{Discussion}

We studied IgG avidity in human fascioliasis. It was measured as a function of hydrogen-bond dissociation using $6 \mathrm{M}$ urea as the eluting agent, and AI was calculated for each case. A cut-off level was suggested to differentiate between acute and chronic cases. According to this level, the majority of cases in the acute phase had low avidity, while those in the chronic stage had high avidity. $\Lambda$ previous study on experimental schistosomiasis reported low avidity antibodies up to the 10th week of infection, aftor which high avidity antibodies were detected [19].
IHAT is the reference standard for diagnosis of acute fascioliasis against which newer assays are compared [20]. However, 4 patients diagnosed by IHAT as having acute fascioliasis gave avidity figures above the cut-off point. It is known that Fasciola worms mature in 3-4 months in the human host, and maturation of the antibody response in other hosts has been reported to extend over a longer period of time [2l]. The 4 patients were probably nearing the end of the incubation period, or they might be harbouring adult worms that were missed by stool examination. Thus, high avidity in a patient diagnosed as incubating fascioliasis points to the need for a revision of the diagnosis and for the performance of more stool examinations.

In the 18 patients with established infection, only 1 had low avidity, together with a positive IHAT. These two findings denote recent worm maturation, i.e. early chronicity. Another patient with chronic in- 
fection had a positive IHAT, but had high avidity. This case could be explained by the relatively high infection intensity (312 eggs/g) with a high antibody level. Reinfection may offer another explanation to these findings.

\section{Conclusion}

IgG avidity ELISA, recently introduced for the serodiagnosis of some parasitic diseases, is useful in human fascioliasis. It confirmed the diagnosis of incubating infection and can thus be introduced as a screening test. Moreover, it distinguished incubating cases from established cases and thus could help determine the time at which infection began.

\section{Acknowledgement}

We greatly appreciate the participation of Dr Adel Zaki, Head, Medical Statistics Department, Medical Research Institute, University of Alexandria, in the statistical analysis of this work.

\section{References}

1. Sampaio-Silva ML et al. Antigenic components of excretory-secretory products of adult Fasciola hepatica recognized in human infections. American journal of tropical medicine and hygiene, 1996, 54(2):146-8.

2. Abou Basha LM, Salem AI, Fadali GA. Ultrastructure of the liver before and after bithionol treatment. Journal of the Egyptian Society of Parasitology, 1990, 20:541-8.

3. Shehab AY et al. Detection of circulating $E / S$ antigens in the sera of patients with fascioliasis by IELISA: a tool of serodiagnosis and assessment of cure. Tropical medicine and international health, 1999 , 4(10):686-90.

4. Knobloch $\mathrm{J}$. Human fascioliasis in Cajamarca/Peru. II. Humoral antibody response and antigenaemia. Tropical medicine and parasitology, 1985. 36(2):91-3.

5. Hedman K, Seppålă I. Recent rubella virus infoction indicated by a low avidity of specific lgG. Joumal of clinical immunology, 1988, 8(3):214-21.
6. Rousseau S, Hedman K. Rubella infection and reinfection distinguished by avidity of IgG. Lancet, 1988, 1(8594): 1108-9.

7. Enders G, Knotek F. Rubella IgG total antibody avidity and IgG subclass spocific antibody avidity assay and their role in the differentiation between primary rubella and rubella reinfection. Infection. 1989, 17(4):218-26.

8. Hedman $\mathrm{K}$ et al. Recent primary toxoplasma infection indicated by a low avidity of specific IgG. Joumal of infectious diseases, 1989, 159(4):736-40.

9. Hedman $K$, Vaheri A, BrummerKorvenkontio M. Rapid diagnosis of hantavirus disease with an lgG-avidity assay. Lancet, 1991, 338(8779):1353-6.

10. El-Zayyat $E$ et al. Evaluation of specific immunogiobulin $G$ avidity enzymeIlnked Immunosorbent assay (IgG avidity ELISA) in diagnosis of early and chronic schistosomiasis. Journal of the Egyptian Society of Parasitology, 1998, 28(3): 739-52.

11. Heshmat MG. Human fascioliasis in Benera province. Egyptian journal of 
medical laboratory sciences, 1995, 1:55-61.

12. Katz NZ, Coelho PM, Pellegrino J. Evaluation of Kato's quantitative method through the recovery of Schistosoma mansoni egos added to human feces. Journal of parasitology, 1970, 56(5): 1032-3.

13. Rivera Marrero CA, Santiago N, Hillyer GV. Evaluation of immunodiagnostic antigens in the excretory-secretory products of Fasciola hepatica. Journal of parasitology, 1988, 74(4):646-52.

14. Lowry $\mathrm{OH}$ et al. Protein measurement with the folin phenol reagent. Journal of biological chemistry, 1951, 193:265-75.

15. Shehab AY. Detection of circulating Fasciola antigens (CFA) and of specific antibodies in the sera of infected patients. A chronological study [Thesis]. Alexandria, Egypi, University of Alexandrla, 1997.

16. Voller A, Bidwell DE, Bartlett A. The enzyme immunoassays in diagnostic medicine. Bulletin of the World Health Organization, 1976, 53(1):55-65.
17. Narita $M$ et al. Immunoglobulin $G$ avidity testing in serum and cerebrospinal fluid for analysis of measles virus infection. Clinical and diagnostic laboratory immunology, 1996, 3(2):211-5.

18. Thomas $\mathrm{HI}$, Morgan-Capner P. The avidity of specific IgM detected in primary rubella and reintection. Epidemiology and infection, 1990, 104(3);489-97.

19. Hassan MM et al. Low avidity antibodies in diagnosis of recent experimental schistosomal infection. Journal of the Egyptian Society of Parasitology, 1994, 24:193-8.

20. Farag HF, Youssof MY, Hassan ME. Antischistosoma and anti-Fasciola antibody levels in single and combined infections. Journal of the Medical Research Institute, 1988, 9:9-18.

21. Chen MG, Mott KE. Progress in assessment of morbidity due to Fasciola hepatica infection: a review of recent literature. Tropical diseases bulletin, 1990, 87:R1-R38. 